\title{
Hidden 19S IgM Rheumatoid Factor in Juvenile Rheumatoid Arthritis
}

\author{
TERRY L. MOORE, ${ }^{(24)}$ ROBERT W. DORNER, TERRY D. WEISS. ANDREW R. BALDASSARE, AND \\ JACK ZUCKNER \\ Division of Rheumatology. Department of Internal Medicine. St. Louis University School of Medicine. St. Louis, \\ Missouri, and Cardinal Glennon Memorial Hospital for Children. St. Louis, Missouri. USA
}

\begin{abstract}
Summary
One-hundred twenty-five serum samples from 82 patients with juvenile rheumatoid arthritis (JRA) were studied for the presence of hidden rheumatoid factor (RF) in an effort to find a better serologic marker to define JRA. Hidden 19S IgM RF was detected by means of a hemolytic assay utilizing the IgM-containing fraction of serum. The IgM fraction was obtained after acid separation of serum on a Sephadex G-200 column. Hidden 19S IgM RF was present in $68 \%$ of patients with seronegative JRA with a mean titer of 1:63. The mean titer for the polyarticular JRA group was $1: 83$, for the pauciarticular JRA group, it was 1:32, and for the systemic type-onset JRA patients, it was 1:32. When disease was active, the mean titer for all JRA patients was 1:108, for the active polyarticular JRA group it was 1:119, for the active pauciarticular JRA, it was 1:97, and for the active systemic JRA patients, it was 1:64. All values were significant at the $P \leq 0.001$ when compared to disease and normal controls.
\end{abstract}

The hemolytic assay for RF on the IgM-containing fraction of serum thus enhances the serologic capabilities of defining JRA.

\section{Speculation}

These studies showing the correlation of disease activity and the presence of hidden rheumatoid factor will aid in evaluating and following disease activity in juvenile rheumatoid arthritis.

Juvenile rheumatoid arthritis (JRA) is a generalized systemic disease of children that involves joints and different organ systems (7). The disorder has protean manifestations with variable modes of onset and patterns of disease (4). Three distinctive types are usually recognized by their presentation during the first 6 months of illness, i.e., systemic, pauciarticular, and polyarticular (3). This disorder with its different modes of onset often creates difficulty in diagnosis. Laboratory aids in diagnosis are usually not helpful because most findings are not specific for JRA (7). Thus, antinuclear antibody, although present in as high as $43 \%$ of patients (9). is found in other connective tissue diseases with greater frequency. Rheumatoid factor (19S IgM) (RF) has been found in only 15 to $20 \%$ of children with JRA by the latex fixation test (LFT). It is most frequently present in the polyarticular group, to a lesser extent in the pauciarticular patients, and rarely in the systemic group (9).

Rheumatoid factors detected by the LFT are classically 19S IgM antibodies directed against the Fc portion of the IgG molecule (16). In the serum, they may circulate unbound or at times bound to $\operatorname{lgG}(1)$. When bound to IgG, they may be undetectable in the serum by the routine LFT (hidden RF). Hidden RF, thus, may only be determined by separation of serum by acid gel filtration into the IgM and IgG fractions. Hidden RF or 19S IgM RF as determined by LFT or hemolytic assay of the IgM-containing fraction of serum after separation by gel filtration at $\mathrm{pH} 4$ was described by the authors in 46 to $59 \%$ of patients with JRA in preliminary studies $(11,12)$. We now report our findings in greatly enlarged patient population. By means of a hemolytic assay, hidden RF has now been identified in $68 \%$ of patients with seronegative JRA. Correlation with disease activity has also been assessed.

\section{MATERIALS AND METHODS}

\section{PATIENT POPULATION}

Serum samples were obtained from children attending the Pediatric Arthritis Clinic and general Medical Clinic of Cardinal Glennon Memorial Hospital for Children at St. Louis University and the offices of Division rheumatologists. All children's legal guardians signed permits for the serum to be obtained. Children with a diagnosis of JRA met criteria established by The Committee on the Classification of JRA of the American Rheumatism Association (3). Activity of disease was defined on a three-point scale as previously described in detail (12): 0 indicated inactive disease: $1+$ activity indicated mild-to-moderate arthritis; and 2+ activity denoted markedly active arthritis and/or extraarticular manifestations. Subjects were categorized into five groups: I, normal controls children ages 1 to 16 (18 patients); 2 , disease controls children ages 3 to 16 ( 30 patients) including individuals with active systemic lupus erythematosus, polymyositis, scleroderma, acute leukemia, ankylosing spondylitis, psoratic arthritis, mixed connective tissue disease, and regional enteritis; 3 , polyarticular JRA (70 samples from 44 children); 4 , pauciarticular JRA (40 samples from 28 children): and 5, systemic JRA ( 15 samples from 10 children). The diagnosis and classification of polyarticular, pauciarticular, or systemic JRA were made on original diagnosis and follow-up.

\section{LABORATORY TEST PROCEDURES}

Sera were subjected to gel filtration on a Sephadex G-200 column $(2.5 \times 85 \mathrm{~cm})$ essentially by the method of Allen and Kunkel (1) as previously described in detail (11). Purity of the IgM fraction was determined by immunodiffusion against rabbit anti-human $\operatorname{IgM}, \operatorname{IgA}$, and $\mathrm{IgG}$. The IgM fraction was completely free of any $\operatorname{IgG}$ or $\lg A$ contamination.

The hemolytic assay was performed on serum and on the IgM and $\mathrm{IgG}$-containing fractions after heat inactivation at $56^{\circ} \mathrm{C}$ for $30 \mathrm{~min}$ and absorption with a 1:5 dilution of washed, packed sheep red blood cells (SRBC) at $37^{\circ} \mathrm{C}$ for $90 \mathrm{~min}$ or until no nonspecific agglutination was seen in microtiter plates with nonsensitized SRBC. The target cell-SRBC were sensitized with a 1:100 dilution of rabbit anti-SRBC IgG hemolysin (Colorado Serum, Denver, $\mathrm{CO})$ as previously described $(12,18)$.

One-tenth $\mathrm{ml}$ of serum or IgM or IgG fraction was diluted serially in $0.15 \mathrm{M}$ veronal-buffered saline containing $0.1 \%$ gelatin 
(Sigma Chemical Co., St. Louis, MO.) and $0.0005 \mathrm{M} \mathrm{MgCl}_{2}$ and $0.00015 \mathrm{M} \mathrm{CaCl}_{2}, \mathrm{pH} 7.4$ (GVB). To each dilution, $0.1 \mathrm{ml}$ of $1 \%$ sensitized SRBC was added. Following incubation at $37^{\circ} \mathrm{C}$ for 60 $\min$ and $60 \mathrm{~min}$ to overnight at $4^{\circ} \mathrm{C}$, the cells were washed with $1 \mathrm{ml}$ of cold GVB and centrifuged for $5 \mathrm{~min}$ at $4^{\circ} \mathrm{C}$ at $2000 \mathrm{rpm}$, and the supernatant was discarded. Next, $1 \mathrm{ml}$ of GVB and $0.4 \mathrm{ml}$ of 1:40 diluted guinea pig serum (previously absorbed with SRBC) as a source of complement were added to the target cells. After incubation for $60 \mathrm{~min}$ at $37^{\circ} \mathrm{C}$ with vortexing every $12 \mathrm{~min}$, the reaction was stopped with $1.5 \mathrm{ml}$ of cold, $0.15 \mathrm{M}$ phosphatebuffered saline, $\mathrm{pH}$ 7.3. The tubes were centrifuged for $5 \mathrm{~min}$ at $4^{\circ} \mathrm{C}$ and $2000 \mathrm{rpm}$. Hemoglobin released into the supernatant was assayed spectrophotometrically at $412 \mathrm{~nm}$. Buffer background and serum background controls and 100\% water hemolysis controls were included in all assays. One tube dilution higher than the highest hemolytic absorbance reading of the buffer-serum control was considered the titer of the antibody. Titers $>1: 16$ were considered positive because that titer had been found to differ significantly from controls in previous studies (12).

The LFT was performed on the whole serum and on the IgMand $\mathrm{IgG}$-containing fractions after heat inactivation for $30 \mathrm{~min}$ at $56^{\circ} \mathrm{C}$ essentially according to Singer and Plotz (16) with commercial test kit (Difco Laboratories, Detroit. MI). Titers $>1: 20$ were considered positive.

\section{STATISTICAL ANALYSIS}

To obtain an estimate of the significance of the median hidden RF titer difference between groups, data were subjected to MannWhitney analysis (17).

\section{RESULTS}

Four JRA patients were RF positive in their serum by the LFT Fifty-nine of 125 samples (47\%) from the JRA patients were RF positive in the IgM-containing fraction by the LFT. No RF activity was noted in the IgG-containing fraction.

Results of the IgM-containing fractions of JRA patients tested for RF by the hemolytic assay were as follows: combined JRA (all subgroups together) positive in 82 of 125 samples (58 of 82 individuals), the subgroups separately showed polyarticular JRA positive in 53 of 70 samples ( 38 of 44 individuals), pauciarticular JRA positive in 20 of 40 samples ( 15 of 28 individuals), systemic JRA positive in 9 of 15 samples (5 of 10 individuals), disease controls 2 of 30 positive ( 1 patient with systemic lupus erythematosus, titer 1:32: I patient with shoulder-hand syndrome, titer 1:32), and healthy controls 0 of 18 individuals (Table 1). The four patients who were RF positive in their serum by the LFT had elevated titers by the hemolytic assay on both their sera and IgM fractions; these patients had polyarticular JRA. These four patients were excluded from further statistical studies. The remaining patients and controls were negative by the hemolytic assay on their sera. No hemolytic RF activity was noted in the IgG fraction. The IgM hemolytic RF activity could be inhibited by preincubation with IgG before performance of the assay. A bar graph (Fig. 1) illustrates the hidden RF titers of the IgM-containing fraction by the hemolytic assay of all the seronegative JRA patients as compared to the combined normal and disease groups. Most JRA patients had titers $>1: 32$, and $49 \%$ had titers of $1: 64$ or higher.

Median hidden RF titers of the IgM-containing fractions from each group were obtained by plotting percentage of cumulative

Table 1. Results of hemolvtic assay for hidden rheumatoid factor

\begin{tabular}{lcc}
\multicolumn{1}{c}{ Subgroup } & Samples positive & Individuals positive $^{{ }^{\prime}}$ \\
Polyarticular JRA & $53 / 70$ & $38 / 44$ \\
Pauciarticular JRA & $20 / 40$ & $15 / 28$ \\
Systemic JRA & $9 / 15$ & $5 / 10$ \\
Disease controls & $2 / 30$ & $2 / 30$ \\
Healthy controls & $0 / 18$ & $0 / 18$ \\
${ }^{\prime}$ Titers $>1: 16$. & &
\end{tabular}

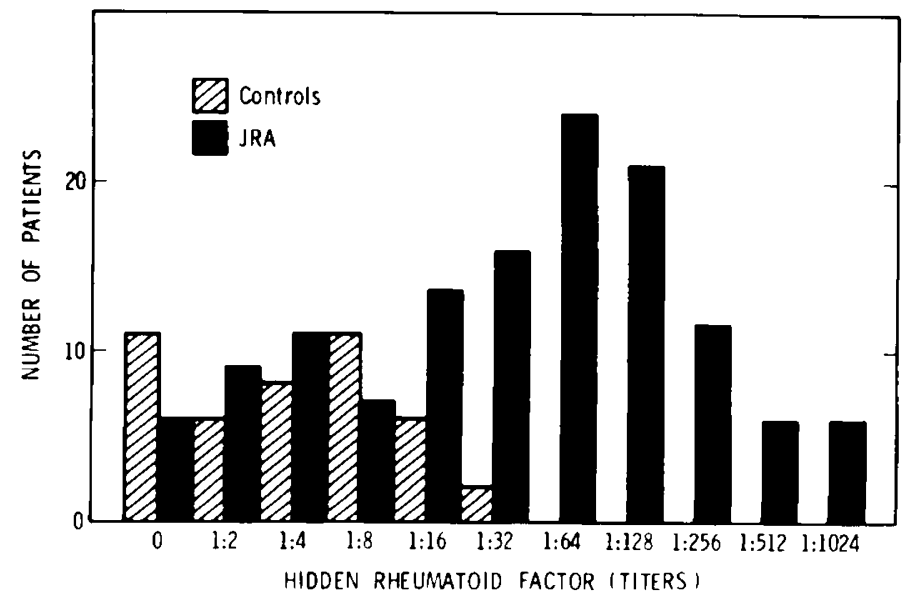

Fig. 1. Bar graph of hidden rheumatoid factor titers in the IgM-containing fractions of the seronegative juvenile rheumatoid arthritis patients compared to the combined normal and disease controls at each individual titer by the hemolytic assay.

Table 2. Median titers of hidden rheumatoid factor

\begin{tabular}{lcc}
\multicolumn{1}{c}{ Group } & $\begin{array}{c}\text { Hidden rheumatoid } \\
\text { factor median titers }\end{array}$ & $\begin{array}{c}\text { Significance of difference } \\
\text { from normal controls }(P)\end{array}$ \\
\hline Healthy controls & $1: 7$ & $N^{2}$ \\
Disease controls & $1: 5$ & \\
Combined controls & $1: 6$ & $<0.001$ \\
& & $<0.001$ \\
Combined JRA & $1: 63$ & $<0.001$ \\
Polyarticular JRA & $1: 83$ & 0.001 \\
Pauciarticular JRA & $1: 32$ & \\
Systemic JRA & $1: 32$ & \\
\hline
\end{tabular}

'By Mann-Whitney analysis.

NS. not significant at $P=0.05$.

positive tests versus serial dilutions. Rank order was then used to obtain an estimate of the significance of the median hidden RF titer difference between groups by subjecting the data to MannWhitney analysis (17). Median titers for each group are given in Table 2. Patients with JRA had significantly higher titers $(P<$ 0.001 ) than healthy and disease controls. Each JRA subgroup also had significantly higher titers polyarticular $(P<0.001)$, pauciarticular $(P<0.001)$, and systemic $(P=0.001)$.

Patients of the three subgroups were separated according to disease activity. In the total JRA population studies, $90 \%$ with active disease were positive including $94 \%$ with active polyarticular disease, $83 \%$ with active pauciarticular, and $83 \%$ with active systemic JRA (Table 3). Median hidden RF titers for patients with active $(1+$ or $2+$ activity) and inactive $(0$ activity) disease of each subgroup were obtained by plotting percentage of cumulative positive tests versus serial dilutions as shown in Figure 2. Significance of the median-hidden RF titer for active disease was again analyzed by Mann-Whitney analysis (17) (Table 3 ). The combined JRA patients with active disease as well as each of the three subgroups with active disease had significantly higher titers than healthy and disease controls $(P<0.001)$. When disease activity of each group was compared, the combined JRA patients with active disease and the patients with active polyarticular JRA and active pauciarticular JRA had median RF titers significantly different $(P<0.001)$ from that of inactive patients of their respective groups. Inactive pauciarticular and inactive systemic JRA patients' titers did not differ significantly from control values.

\section{DISCUSSION}

Serologic markers for JRA have previously been found in only a relatively small number of cases $(9)$. For example, only about 15 
Table 3. Patients with active and inactive seronegative JRA having hidden rheumatoid factors titers $>1: 16$ and their median titers

\begin{tabular}{|c|c|c|c|c|c|}
\hline Group & $\begin{array}{c}\text { Hidden RF titer }>1: 16 \\
\text { patients }\end{array}$ & $\%$ & $\begin{array}{l}\text { Hidden rheumatoid } \\
\text { factor median titer }\end{array}$ & $\begin{array}{l}\text { Significance of difference } \\
\text { from normal controls }(P)\end{array}$ & $\begin{array}{c}\text { Significance of difference }{ }^{1} \\
\text { from inactive disease of each } \\
\text { group }(P)\end{array}$ \\
\hline Combined JRA, active & $70 / 78$ & 90 & $1: 108$ & $<0.001$ & $<0.001$ \\
\hline Combined JRA, inactive & $12 / 47$ & 26 & $1: 19$ & $<0.001$ & \\
\hline Polyarticular JRA, active & $46 / 49$ & 94 & 1:119 & $<0.001$ & $<0.001$ \\
\hline Polyarticular JRA, inactive & $7 / 21$ & 33 & $1: 28$ & $<0.001$ & \\
\hline Pauciarticular JRA, active & $19 / 23$ & 83 & 1:97 & $<0.001$ & $<0.001$ \\
\hline Pauciarticular JRA, inactive & $1 / 17$ & 6 & $1: 7$ & $\mathrm{NS}^{2}$ & \\
\hline Systemic JRA, active & $5 / 6$ & 83 & $1: 64$ & $<0.001$ & $\mathrm{NS}^{2}$ \\
\hline Systemic JRA, inactive & $4 / 9$ & 44 & $1: 23$ & NS: & \\
\hline
\end{tabular}

' By Mann-Whitney analysis.

${ }^{2} \mathrm{NS}$, not significant at $P=0.005$.

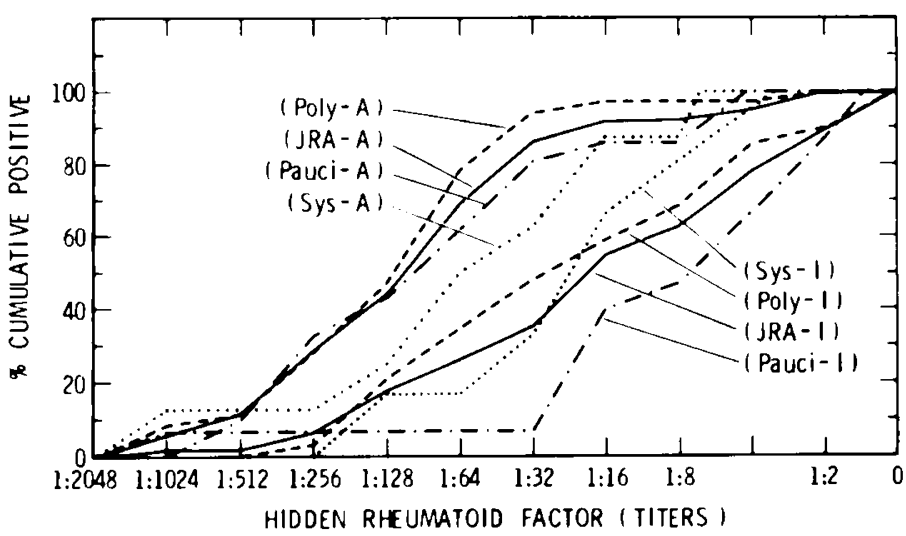

Fig. 2. Graph of percentage of cumulative positive tests by the hemolytic assay for the combined juvenile rheumatoid arthritis group and each subgroup with active and inactive disease versus serial dilutions of the IgM-containing fractions. JRA, combined JRA patient group; Poly, polyarticular JRA patients; Pauci, pauciarticular JRA patients; $S_{y}$ 's, systemic JRA patients; A, active disease; and I, inactive disease.

to $20 \%$ of cases have RF. In this study, hidden RF has been found in the IgM fraction of sera by the hemolytic assay in $68 \%$ of JRA patients who were seronegative by the LFT. The results of the present study confirm our previous finding which had been based on a smaller number of patients $(11,12)$ that hidden RF can be found in a high percentage of patients with JRA. Therefore, it potentially can prove to be a valuable diagnostic aid. This is particularly so in patients with active disease. In the total JRA population studies, $90 \%$ with active disease were positive. Ninetyfour percent with active polyarticular disease were positive. $83 \%$ with an active pauciarticular disease were positive, and $83 \%$ with active systemic JRA were positive. Thus, the testing for hidden $\mathrm{RF}$ in patients with active disease could prove most advantageous for differential diagnosis as well as offering a possible means of monitoring disease activity.

The significance of hidden RF in JRA is of great interest. Hidden RF overlaps into the three classic subgroups, namely patients with polyarticular, pauciarticular, and systemic type of disease. Thus, the overlap of hidden RF into all 3 groups intimates that a common antigenic exposure might be present in all. The likelihood that they are thus all one disease with varied onsets and different manifestations is suggestive, contradicting the possibility that each subgroup represents a different disease.

The significance of RF as a mediator of pathogenesis has always been debated. The presence of 19S IgM RF in high titer in adults has been associated with more severe joint disease, subcutaneous nodules, elevated erythrocyte sedimentation rate (ESR), vasculitis, systemic manifestations, and hypocomplementemia $(6,10,20,21)$. In children, previous studies have shown a correlation of elevated levels of anti-IgG globulins with disease activity (2), subcutaneous nodules $(2,5,8)$, elevated ESR (2), hypocomplementemia (2), and older age of onset $(5,8)$. Hidden RF had no correlation with sex, age of onset of disease, duration of disease, and different laboratory parameters including complete blood count, ESR, antinuclear antibody, and immunoglobulin levels (IgG, $\operatorname{IgM}$, and $\operatorname{IgA})(12)$. However, it did correlate with positive LFT and sheep cell agglutination test on the IgM fraction and activity of disease (12) documented by the present study. Complement consumption has been associated with disease activity in polyarticular JRA, presumably secondary to immune complexes (14). RF (19S IgM) has been shown to fix complement by the classic pathway (18). The IgM fraction from adult RF patients when subjected to the hemolytic assay has been shown to unmask the full in vitro complement-fixing ability of RF, and hence lytic potential (19). Hidden RF when separated from IgG is capable of demonstrating its full complement fixing ability and lytic potential. The ability to fix complement by the classical pathway results in the release of anaphylatoxins ( $\mathrm{C} 3 \mathrm{a}$ and $\mathrm{C} 5 \mathrm{a})$, chemotaxins $(\mathrm{C} 3 \mathrm{a}, \mathrm{C} 5 \mathrm{a}$, and $\mathrm{C} 5 \mathrm{~b} 67$ ), and subsequent fixing of $\mathrm{C} 8$ and $\mathrm{C} 9$ with resultant target cell lysis (13). The release of effector molecules and terminal component activation leads to increased inflammation and tissue damage. Hidden RF being bound to $\operatorname{lgG}$ in the serum may cause configurational changes in the $19 \mathrm{~S} \mathrm{IgM}$ molecule, thereby increasing its complement-fixing ability: this is a possibility because previous studies have shown that RF not bound usually is weakly complement fixing (15). Hidden RF may also represent a low percentage of RF that is complement-fixing due to its ability to bind IgG and form immune complexes, whereas most RF does not avidly bind human $\operatorname{IgG}$ and form immune complexes, and, therefore, is noncomplement-fixing IgM antibody. The shift in antibody production would depend on the underlying antigen selectively altering $\operatorname{IgG}$ molecules which would bind to the $19 \mathrm{~S}$ IgM RF. The resultant hidden RF may show specificity for antigen. Thus, the ability to define a hidden RF that fixes complement may explain its significant correlation with disease activity.

\section{REFERENCES AND NOTES}

1. Allen, J. C.. and Kunkel, H. G.: Hidden rheumatoid factors with specificity for native gamma globulins. Arthritis Rheum.. 9: 758 (1966).

2. Bianco. N. E.. Panush. R. S.. and Stillman. J. S.: Immunologic studies of juvenile rheumatoid arthritis. Arthritis Rheum.. 14: 685 (1971).

3. Brewer, E. J.. Bass, J., Baum. J.. Cassidy. J. T.. Fink. (.. Jacobs, J., Hanson. V. Levinson. J. E.. Schaller. J.. and Stillman, J. S.: (urrent proposed revision of JRA criteria. Arthritis Rheum., 20): (Suppl.): 195 (1977).

4. Calabro, J. J.. Holgerson. W. B., Sonpal. G. M.. and Khoury, M. I.: Juvenile rheumatoid arthritis: a general review and report of 100 patients observed for 15 years. Sem. Arthritis Rheum., 5: 257 (1976).

5. Cassidy. J. T., and Valkenberg, H. A.: A five-year prospective study of rheuma- 
toid factor tests in juvenile rheumatoid arthritis. Arthritis Rheum., 10:83 (1967).

6. Franco, A. E., and Schur, P. H.: Hypocomplementemia in rheumatoid arthritis. Arthritis Rheum.. 14: 231 (1971).

7. Grossman. B. J.. and Mukhopaưhyay D.: Juvenile rheumatoid arthritis. Curr Probl. Pediatr., 5: 3 (1975).

8. Hanson. V.. Drexler, E., and Kornreich. H.: The relationship of rheumatoid factor to age of onset of juvenile rheumatoid arthritis. Arthritis Rheum.. 12:82 (1969)

9. Levinson. J. E.. Balz. G. P.. and Hess. E. V.: Report of studies on juvenile rheumatoid arthritis. Arthritis Rheum.. 20: (Suppl.): 189 (1977).

10. Mongan. E. S.. Cass. R. M.. Jacox R. F.. and Vaughan. J. H.: A study of the relation of seronegative and seropositive rheumatoid arthritis to each other and to necrotizing vasculitis. Am. J. Med., 47: 23 (1969)

11. Moore. T. L.. Dorner. R. W.. and Zuckner. J.: Hidden rheumatoid factor in seronegative juvenile theumatoid arthritis. Ann. Rheum. Dis.. 33: 255 (1974).

12. Moore, T. L.. Zuckner, J.. Baldassare, A. R.. Weiss, T. D., and Dorner, R. W. Complement-fixing hidden rheumatoid factor in juvenile rheumatoid arthritis. Arthritis Rheum.. 21: 935 (1978).

13. Muller-Eberhard. H. J.: The serum complement system. In: P. A. Miescher. H J. Muller-Eberhard: Textbook of Immunopathology. p. 45 (Girune \& Stratton. New York, 1976)

14. Pachman. L. M.. and Baldwin. S. M.: Assays of complement in polyarticular juvenile rheumatoid arthritis. Arthritis Rheum.. 20): (Suppl.): 467 (1977).

15. Schmid, F. R., Roitt. I. M., and Rocha, M. J.: Complement fixation by a twocomponent antibody system: immunoglobulin $G$ and immunoglobulin $M$ antiglobulin (rheumatoid factor), paradoxical effect related to immunoglobulin G concentration. J. Exp. Med., 132: 673 (1970).

16. Singer. J. M., and Plotz. C. M.: The latex fixation test. I. Application to the serologic diagnosis of rheumatoid arthritis. Am. J. Med.. 21: 888 (1956).
17. Sokal, R. R., and Rohlf, E. J.: In: D. Kennedy, R. B. Park: Introduction to Biostatistics. p. 217 (W. Freeman and Company. San Francisco. (a.. 1973).

18. Tanimoto, K. Cooper, N. R., Johnson. J. S., and Vaughan. J. H.: Complement fixation by rheumatoid factor. J. Clin. Invest. 5.5: 437 (1975).

19. Taylor-Upsahl, M. M.. Johnson. P. M., Mellbye, O. J.. and Natvig, J. G.: A study of complement fixation by rheumatoid factor using a hemolytic assay system. Clin. Exp. Immunol., 28: 204 (1977).

20. Vaughan. J. H., Chihara. T., Moore. T. L.. Robbins, D. L.. Johnson, J. S., and McMillan. R. W.: Rheumatoid factor-producing cells detected by direct hemolytic plaque assay. J. Clin. Invest.. 58 : 933 (1976).

21. Veys, E. M Gabriel, P A.. Coigne. E., and Mielants. $H$. Rheumatoid factor and serum IgG, IgM. and IgA levels in rheumatoid arthritis with vasculitis. Scand. J. Rheumatol., s: 1 (1976).

22. Presented in part at the annual meeting of the American Rheumatism Association, Denver CO. May, 1979

23. The authors gratefully acknowledge the technical assistance of Wayne Sheridan and Orlando Moncado.

24. Requests for reprints should be addressed to: Terry L. Moore. M.D., St. Louis University School of Medicine. Division of Rheumatology. Room 215 Doisy Hall. 1402 South Grand Boulevard. St. Louis. MO 63104 (USA)

25. This research was supported in part by a Clinical Investigator Award AM-00364 from the National Institute of Arthritis. Metabolism, and Digestive Diseases and in part by grant RR-05388 from the National Institutes of Health and a grant from the Variety Club of St. Louis through the Juvenile Rheumatoid Arthritis Parent's Group. Dr. Moore is a recipient of a Clinical Investigator Award from the National Institute of Arthritis. Metabolism. and Digestive Diseases.

26. Received for publication November 15,1979.

27. Accepted for publication February 5, 1980 